\title{
Kat Isıtmasında Yüzer Döşeme ve Faz Değiştiren Malzeme Kullanımının Enerji Verimliliğine ve Konfor Koşullarına Etkisi
}

\author{
Ersin Haydaraslan ${ }^{* 1}$, Burhan Çuhadaroğlu ${ }^{2}$, Yalçın Yaşar $^{3}$
}

\section{ÖZ}

Günümüzde ülkelerin gelişmişlik düzeylerine ilișkin tüm sınıflandırmalarda enerji önemli bir yer tutmaktadır. Ülkelerin geleceğe yönelik yaptığı bütün planlamalarda enerji kullanım oranı etkin bir parametre olarak göz önüne alınmaktadır. Buna bağlı olarak enerji kullanımının düşürülmesi amacıyla yapılan bilimsel çalışmalar önem kazanmaktadır. Bu çalışmada, ara kat döșemelerinde yalıtım ve faz değiștiren malzeme (FDM) kullanılmasının enerji verimliliği ve konfor koşulları üzerindeki etkileri incelenmiştir. Bodrum, zemin ve iki normal kattan oluşan örnek bir binada eş zamanlı olarak 1sıtılan ve 1sıtılmayan ortamlardan oluşan farklı senaryolar üzerinde çalışma yapılmıştır. Bu senaryolarda yalıtımsız, yalıtımlı ve yalıtıma ek FDM içeren bir katmanın olduğu üç farklı döşeme tipi kullanılarak, bu parametrelerin ortamların 1sı yüklerine, ortam sıcaklığına ve enerji kullanımına etkileri incelenmiştir. Çalışmada elde edilmiş olan bulgulara göre; döşeme ve tavanda yalıtım ve FDM kullanılması ile ortamların 1sı yükü düşmektedir. Aynı zamanda ortam sıcaklıklarının ayar sıcaklığına daha yakın olması ile birlikte isıl konfor koşullarının iyileşmekte olduğu belirlenmiştir. Çalışma sonuçları göstermektedir ki; döşeme ve tavanlarda yalıtım ve FDM kullanımı, yıllık enerji kullanımını aşağıya çekmekte ve enerji verimliliğinde önemli bir artış sağlamaktadır.

Anahtar Kelimeler: Enerji verimliliği, ssıl konfor, yüzer döşeme, faz değiştiren malzeme (FDM)

\section{The Effect of Floating Floor and Phase Changing Materials on Energy Efficiency and Comfort Conditions in Individual Heating}

\begin{abstract}
The energy takes an important shares in the nowadays classifications on the country development level. The energy consumption rate is considered as an effective parameter in all the future planning of the countries. Accordingly, scientific studies are important to reduce energy consumption. In this study, the effects of using insulation and phase change material (PCM) on the floors were investigated on energy efficiency and comfort conditions. In a building consisting of basement, ground floor and two normal floors, different scenarios were studied for simultaneously heated and unheated zones. In these scenarios, the effects of these parameters on the heat loads, zone temperature and energy consumption were investigated using three different types of flooring (uninsulated, insulated, and insulated and including PCM). According to the findings obtained from the study, the heat load of the zones decreased with the use of the insulation and PCM on the floor and ceiling. At the same time, it was determined that the thermal comfort conditions were improving as the zone temperatures were closer to the set point temperature. The results show that the use of insulation and PCM in floors and ceilings decrease the annual energy consumption and provides a significant increase in the energy efficiency.
\end{abstract}

Keywords: Energy efficiency, thermal comfort, floating floor, phase change material (PCM)

\footnotetext{
" İletișim Yazarı

Geliş/Received : 08.05 .2020

Kabul/Accepted : 30.06 .2020

1 Recep Tayyip Erdoğan Üniversitesi, Teknik Bilimler Meslek Yüksekokulu, Elektrik ve Enerji Bölümü, Rize, ersin.haydaraslan@erdogan.edu.tr ORCID: 0000-0002-3142-9518

2 Karadeniz Teknik Üniversitesi, Mühendislik Fakültesi, Makine Mühendisliği Bölümü, Trabzon, burhan@ktu.edu.tr ORCID: 0000-0002-9144-498X

3 Karadeniz Teknik Üniversitesi, Mimarlık Fakültesi, Mimarlık Bölümü, Trabzon, e-posta : yyasar@ktu.edu.tr ORCID: 0000-0003-1899-750X
} 


\section{GİRIŞ}

Artan nüfus ve tüketim çeşitliliği ile birlikte enerji gereksinimi de artmaktadır. Konvansiyonel enerji kaynaklarının hızla tükenmesi nedeniyle ülkeler tarafından hazırlanan gelişme planlarının ana başlığını enerji konusu oluşturmaktadır. Enerjinin büyük bir kısmı fosil kaynaklardan sağlanmaktadır. Fosil kaynakların yakın bir gelecekte tükenecek olmasının yanı sıra, bu kaynakların kullanımı ile atmosfere salınan sera gazı miktarının artması önemli bir risk oluşturmaktadır. Sera gazlarının artışı ise uzun dönemde iklim değişikliğine neden olmaktadır. İklim değişikliğinin etkilerinin azaltılması için aralarında Türkiye'nin de olduğu birçok ülke ortak çalışma yürütmektedir $[1,2]$. İklim değişikliğinin etkilerinin somut bir şekilde görünüyor olmasından dolay1 bu alanda farkındalık artmıştır. Bu farkındalık ile enerjinin yaklaşık olarak \%40’nın kullanıldığı bina sektöründe enerji kullanımının azaltılması için çalışmalar yapılmaktadır. Bunun için Avrupa Birliği 2002 yılında Binalarda Enerji Performansı Direktifini (EPBD) yayımlamıştır [3]. Avrupa'daki üye ülkeler için hazırlanan enerji direktifinde 2020 yılının sonuna kadar inşa edilen tüm yeni binaların yaklaşık sıfır enerjili bina (nZEB) olması beklenmektedir [4]. Bu yönetmelik Avrupa Birliğine üye ve Türkiye gibi aday olan ülkeleri de kapsamaktadır.

Teknolojinin gelişimi ile binalar tarih boyunca değişime uğramıştır ve en köklü değişiklik 19. yüzyılda meydana gelmiştir. İnşaat süresi kısalmış ve artan nüfus ile yapılaşma hızlanmıştır. Yaşanan ekonomik ve sosyal gelişmeler ile bina kullanıcılarının yaşam kalitesi artmıştır. Yaşam kalitesinin artması ile enerji kullanımında artış yaşanmaktadır. Yapılan çalışmalar en fazla enerji kullanımının konutlarda olduğunu göstermektedir [5]. Dolayısıyla bina sektörü, sera gazları salınımının azaltılmasında anahtar sektördür. Avrupa Birliği ülkelerinde kullanılan enerjinin \%40’1 ve salınan CO2 miktarının \%36'sı bina kaynaklıdır [6]. Binalardaki iklimsel ve konumsal parametrelerde, binaya ait tasarım parametrelerinde ve yapı sistem parametrelerinde yapılabilecek iyileştirmelerle, binanın enerji performansı \%30 oranında artırılabilmektedir. EPBD’ye göre binaların enerji performansını etkileyen parametreler binanın ısıl özellikleri (1S1 köprüleri, yalıtım vb.), mekanik sistemler, aydınlatma, tasarım, konum ve yönlenme, pasif sistemler ve iç ortam koşulları olarak belirtilmektedir. Bina kullanıcıları için uygun iç ortam konfor koşullarının sağlanmasında binaların kabuğu önemlidir. Bina kabuğunun enerji performansı dış duvar, döşeme, çatı, tavan, pencere ve kapıların enerji performansına bağlıdır. Bu nedenle binaların enerji performansının artırılması için bina kabuğu elemanlarının enerji performansının iyileştirilmesi için çalışmalar yapılmıştır $[7,8,9]$. Özellikle mevcut binaların enerji kullanımlarının azaltılması için duvar ve döşemelerde yalıtımın kullanılması ve yalıtım kalınlığının etkilerini inceleyen çalışmalar bulunmaktadır [10, 11]. Delmastro vd. [10]; binaların enerji performanslarının iyileştirilmesi konusunda yaptıkları çalışmada, ara kat döşemelerine yalıtım eklenmesi durumunu incelemişlerdir. Çalışmada döşemelere eklenen yalıtımın enerji 
kullanımını azalttığını belirtmişlerdir. Kurnitski vd. [12]; tavana yalıtım eklenmesinin enerji performansını alınan diğer önlemlerle birlikte \%16 oranında artırmakta olduğu bulgusuna ulaşmışlardır. Ayrıca, Çuhadaroğlu [13]; kat 1sıtması yapılan binalarda alt ve üst katların eş zamanlı olarak ısıtılmamasından kaynaklanan enerji kaybını ve bu durumun iç ortam sıcaklıklarına etkisini incelemiştir. Çalışmada ara kat döşemelerinde yalıtımın kullanılmasının ısıl konfor üzerinde önemli olduğu sonucuna ulaşılmıştır.

Uluslararası Enerji Ajansı (IEA)'nın yaptığı projeksiyon çalışmalarına göre 2030 yılına kadar enerji performansı yüksek binaların inşasını artırmak ve farklı bina tiplerindeki enerji ihtiyaçlarının azaltılması için yenilikçi çözümler ve iş modelleri gerekmektedir. IEA, bina kabuğunda inovasyon gereken alanları farklı başlıklara ayırmıştır. Bu başlıklar; hava akışı, hava sızdırmazlığı ve havalandırma kontrolleri, geliştirilmiş pencereler, binaya entegre depolama sistemleri ve yenilenebilir enerji teknolojileridir. Binaya entegre depolama sistemleri ve yenilenebilir enerji teknolojileri altında faz değiştiren malzemeler (FDM) yer almaktadır [14]. Avrupa Birliği’nin 2015 yılında yayınladığı "Binalarda enerji verimliliği çözümleri için yeni malzemeler ve teknolojiler geliştirilmesi" adlı raporunda enerji depolamanın 2025 y1lında \%60-75 oranlarında enerji etkinliği sağlayacağı belirtilmiştir ve FDM'lerin kullanım yoğunluğunun artırılması üzerinde durulmuştur [15]. Bu doğrultuda binalarda enerji kullanımının azaltılması için, bina konstrüksiyonlarında FDM'ler kullanılmaya başlanmıştır. FDM'ler dış etmenlerin etkisiyle hal değiştiren malzemeler olarak tanımlanmaktadır. Termodinamik açıdan ise FDM'ler entropi değişimi nedeni ile 1sıyı emen ya da serbest bırakan malzemelerdir. Malzeme ısısının bu bölümü, malzemenin kütlesi ile ilgilidir ve malzemenin gizli ısısı olarak tanımlanmaktadır. Gizli 1sı erime sırasında malzeme tarafindan emilebilir ya da donma sırasında serbest bırakılabilir. FDM'lerin birçok tipi vardır ancak yapılan çalışmalara göre organik, inorganik ve karışım olarak üç ana grupta sınıflandırılabilir. [16]. FDM'ler elektronik ekipmanlardan gıda sektörüne kadar geniş bir alanda kullanılmasıyla birlikte, binalarda ısıtma ve soğutma uygulamalarının verimliliğinin arttırılmasında bir enerji depolama sistemi olarak kullanılabilmektedir [17]. Binalarda sıva, dolgu malzemeleri gibi yapı malzemelerinin içine karıştııllarak ya da alçı levhalar gibi yapı malzemelerinde kullanılmaktadır. FDM'lerin binalarda kullanımı ile ilgili, yaz aylarında soğutma yükünü düşürmek için çalışmalar yapılmıştır [18-25]. Bu çalışmalarda faz değiştiren malzemenin tipi, katman kalınlığı, katmanın duvar içindeki pozisyonu, erime sıcaklığ 1 vb. parametrelerin, iklime ve bina karakteristiğine uygun olarak belirlenmesi gerektiğinden bahsedilmektedir. Binalara uygun FDM parametreleri her iklim tipinde farklılık göstermiştir. Kış aylarında 1sıtma yükünü düşürmek için de çalışmalar yapılmıştır [26-29]. Bu çalışmalarda, yine soğutma yükünü düşürmeyi amaçlayan çalışmalardaki parametreler iklime ve bina karakteristiğine uygun olarak belirlenmiştir. Nemli llıman iklime sahip bölgelerde ise hem 1sıtma, hem de soğutma yükünü düşürmeye yönelik çalışmalar yapılımıştır [30-32]. Bu çalışmalardan Wang vd. [22], sıcak bir iklimde yaz günleri soğutma yükünü düşürmek 
için duvar içinde faz değiştiren malzeme kullanmışlardır. Çalışmanın parametreleri, FDM tipi, FDM katman kalınlığı ve FDM'nin duvar içindeki konumudur. Çalışmada, dış ortamdan iç ortama olan 1sı transferi FDM katman kalınlığı arttıkça azalmıştır. En uygun FDM katman konumunun her bir erime sıcaklığında değiştiğini, $31^{\circ} \mathrm{C}$ erime sıcaklığında en uygun konum duvarın iç kısımda olurken, $35^{\circ} \mathrm{C}$ erime sıcaklığında duvarın ortasında bulunduğunda en iyi performans gösterdiğini belirtmişlerdir. İnceledikleri altı FDM'den en iyi performans $14{ }^{\circ} \mathrm{C}$ erime sıcaklığına sahip olanın, 20 mm kalınlıkta ve duvarın dış kısmındayken gösterdiği sonucuna ulaşmışlardır. En iyi performansa sahip FDM'nin 1sı transferini \%34,9'a kadar düşürdüğünü belirtmişlerdir. Diğer bir çalışmada Karaoulis vd. [33], iki tanesi sıcak kuru, bir tanesi sıcak ve çok nemli iklime sahip olmak üzere üç ilde faz değiştiren malzemenin dış duvarda, iç duvarda ve tavanda kullanımının enerji kullanımına etkisini belirlemişlerdir. Çalışmada genel olarak binalardaki aşırı 1sınma ve soğuma sorununun FDM ile çözülebileceği sonucuna ulaşmışlardır. Bu değerlendirmeler ışı̆̆ında bu çalışmada, ara kat döşemelerinde yalıtım ve FDM kullanılmasının 1sı yüküne, ortam sıcaklığına ve enerji kullanımına etkisi incelenmiştir. Soğuk iklim bölgesindeki bir il için ara kat döşemelerinde yalıtımın olmadığı durumda ısı yükü, ortam sıcaklığ1 ve enerji kullanım düzeyi belirlenmiştir. Bu veriler referans alınarak binadaki katların farklı zaman ve sıcaklıklarda kullanılmasına bağlı çeşitli senaryolar geliştirilmiştir. Bu senaryolarda farklı döşeme ve tavan tipleri uygulanarak yalıtımın ve FDM'nin etkileri incelenmiştir.

\section{YÖNTEM}

Çalışma kapsamında ara katlarda yüzer döşeme uygulanmasının ve döşeme ve tavanda FDM kullanılmasının ortamların ısı yüküne, ortam sıcaklığına ve enerji kullanımına olan etkisi teorik olarak incelenmiştir. Hesaplamalar, çalışmada kullanılan bina özellikleri ve sonuçların karşılaştırılması amacıyla oluşturulan farklı senaryolar için yapılmıştır.

\subsection{Hesap Yöntemi}

Isı yükü, ortam sıcaklığı ve yıllık enerji kullanımının hesaplanması için ASHRAE’nin 1sıl denge yaklaşımı kullanılmıştır. Isıl denge yaklaşımının temeli, bina kabuğuna Termodinamiğin I. yasasının (enerjinin korunumu) uygulanmasıdır [34]. Bu yaklaşım binanın her bir yüzeyinin dış ve iç ortama bakan kısımları ile iç ortamları çevreleyen her bir ortama uygulanır (Şekil 1.)

İç yüzey için ısıl denge;

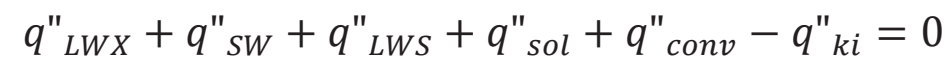

denklemine göre belirlenir. Dış yüzey için ısıl denge ise; 


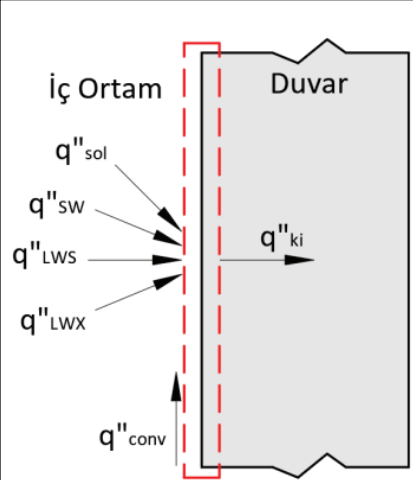

a)

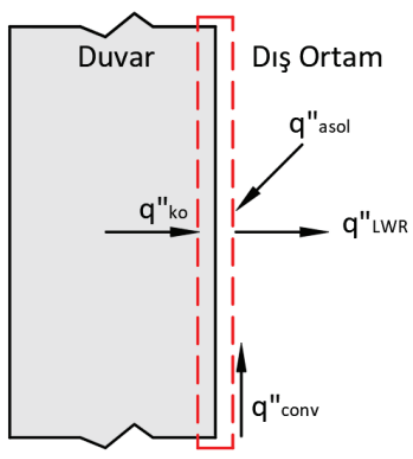

b)

Şekil 1. Isıl Denge Yaklaşımı: a) Iç Yüzey, b) Dış Yüzey

$q^{\prime \prime}{ }_{\text {asol }}-q^{\prime \prime}{ }_{L W R}-q{ }{ }_{\text {conv }}+q^{\prime \prime}{ }_{k o}=0$

denklemine göre belirlenir. Denklem (1) ve (2)'deki q” ${ }_{\text {conv }}$ ortam sıcaklığına göre hesaplanmaktadır. Ortam sıcaklığı ise iç ortam ısıl denge yaklaşımına göre belirlenir (Şekil 2).

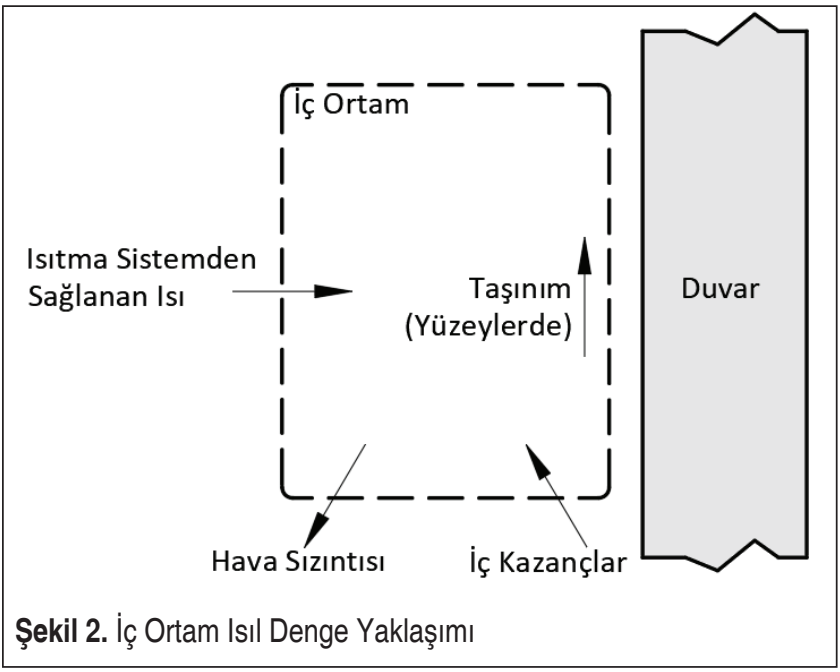

Bu yaklaşımda;

$C_{z} \frac{d T_{z}}{d t}=\sum_{i=1}^{N_{s l}} \dot{Q}_{i}-\sum_{i=1}^{N_{y \text { üzey }}} h_{i} A_{i}\left(T_{z}-T_{s i}\right)-\sum_{i=1}^{N_{\text {ortam }}} \dot{m}_{i} C_{p}\left(T_{z}-T_{z i}\right)-\dot{m}_{\text {inf }} C_{p}\left(T_{z}-T_{\infty}\right)+\dot{Q}_{s y s}$ 
denklemi kullanılmaktadır. Burada;

$$
\begin{aligned}
& C_{z} \frac{d T_{z}}{d t} \quad \text { : Ortamda depolanan 1s1 enerjisi } \\
& \sum_{i=1}^{N_{s l}} \dot{Q}_{i} \quad \text { : İç 1sı yükleri toplamı }
\end{aligned}
$$

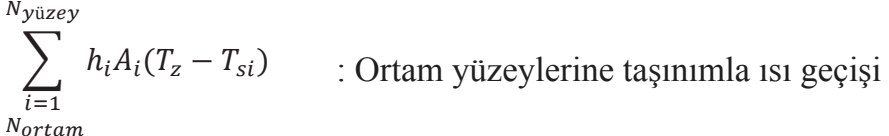

$$
\begin{aligned}
& \sum_{i=1}^{N_{\text {ortam }}} \dot{m}_{i} C_{p}\left(T_{Z i}-T_{z}\right) \quad \text { : İç ortamdan komşu iç ortamlara hava sızıntısı ile 1sı geçişi } \\
& \dot{m}_{\text {inf }} C_{p}\left(T_{\infty}-T_{z}\right) \quad \text { : İç ortamdan dış ortama hava sızıntısı ile 1sı geçişidir. }
\end{aligned}
$$

Daimi durumda ortamda depolanan 1sı enerjisi göz ardı edilirse Denklem (3);

$$
\dot{Q}_{s y s}=-\sum_{i=1}^{N_{s l}} \dot{Q}_{i}+\sum_{i=1}^{N_{y \text { üzey }}} h_{i} A_{i}\left(T_{z}-T_{s i}\right)+\sum_{i=1}^{N_{\text {ortam }}} \dot{m}_{i} C_{p}\left(T_{z}-T_{z i}\right)+\dot{m}_{\text {inf }} C_{p}\left(T_{z}-T_{\infty}\right)
$$

şeklinde yazılır. Burada taşınım katsayısı $h_{i}$, seçilecek bir korelasyona göre belirlenir. $\dot{Q}_{\text {sys }}$ aynı zamanda;

$$
\dot{Q}_{\text {sys }}=\dot{m}_{\text {sys }} C_{p}\left(T_{\text {sup }}-T_{z}\right)
$$

denklemi ile hesaplanabilir. Burada $T_{\text {sup }}$ ortamın 1sıtılması için 1sıtma cihazı tarafindan sağlanması gereken havanın sıcaklığıdır (ayar sıcaklığı). Ortama ait ısıl yük ise $\dot{Q}_{y u ̈ k}=-\dot{Q}_{s y s}$ eşitliği ile elde edilir. Denklem (4)'te $T_{\infty}$ yıl içindeki en düşük dış ortam sıcaklığıdır. İç ortam sıcaklığı $T_{z}$ ise Denklem (3) ve (5)'ten çekilerek;

$$
T_{z}^{t}=\frac{\sum_{i=1}^{N_{s l}} \dot{Q}_{i}^{t}+\dot{m}_{\text {sys }} C_{p} T_{\text {sup }}^{t}+\left(C_{z} \frac{d T_{z}}{\delta t}+\sum_{i=1}^{N_{\text {yüzey }}} h_{i} A_{i} T_{s i}+\sum_{i=1}^{N_{\text {ortam }}} \dot{m}_{i} C_{p} T_{z i}+\dot{m}_{\text {inf }} C_{p} T_{\infty}\right)^{t-\delta t}}{\frac{C_{z}}{\delta t}+\left(\sum_{i=1}^{N_{y u ̈ z e y}} h_{i} A_{i}+\sum_{i=1}^{N_{\text {ortam }}} \dot{m}_{i} C_{p}+\dot{m}_{\text {sys }} C_{p}\right)}
$$

denklemine göre hesaplanır. Bu denklemlerin eş zamanlı olarak çözülmesi için EnergyPlus ile entegre çalışan DesingBuilder bina enerji simülasyon programı kullanılmıştır. Program herhangi bir faz değişiminin olmadığı duvar konstrüksiyonlarında "Conduction Transfer Function (CTF)" algoritması ile çözüm yapmaktadır. Bu algoritmaya göre iç tarafta 1sı akısı zaman bağımlı olarak;

$$
q^{\prime \prime}{ }_{k i}(t)=-Z_{o} T_{i, t}-\sum_{j=1}^{n z} Z_{j} T_{i, t-j \delta}+T_{o} T_{o, t}+\sum_{j=1}^{n z} Y_{j} T_{o, t-j \delta}+\sum_{j=1}^{n q} \Phi_{j} q^{\prime \prime}{ }_{k i, t-j \delta}
$$


ve dış tarafta 1sı akısı zaman bağımlı olarak;

$q^{\prime \prime}{ }_{k o}(t)=-Y_{o} T_{i, t}-\sum_{j=1}^{n z} Y_{j} T_{i, t-j \delta}+X_{o} T_{o, t}+\sum_{j=1}^{n z} X_{j} T_{o, t-j \delta}+\sum_{j=1}^{n q} \Phi_{j} q^{\prime \prime}{ }_{k o, t-j \delta}$

denklemlerine göre belirlenir. Duvar konstrüksiyonunda faz değiştiren malzeme kullanılması durumunda ise "Finite Difference" algoritması kullanılmaktadır [35]. Binanın enerji kullanımı ise Denklem (4) ve (6)'nın y1l boyu saatlik hesaplanmasına (dinamik hesap yöntemi) bağlı olarak elde edilir. Buna göre binada 1sıtma için yıllık enerji kullanımı;

$\dot{Q}_{\text {kullanım }}=\frac{\sum \dot{Q}_{\text {saatlik,yük }} x\left(1+\frac{I D K}{100}\right)}{C O P}$

denklemine göre belirlenir.

\subsection{Bina Bilgileri}

Dördüncü derece gün bölgesinde bulunan Erzurum'da olduğu varsayılan bir bina, bodrum, zemin ve iki normal kattan oluşmaktadır. Bina kullanılmayan çatı arasına sahip kırma çatı olarak modellenmiştir. Duvar, döşeme, pencere, çatı gibi yapı malzemeleri detayları Binalarda Isı Yalıtım Kuralları Türk Standardında (TS 825) [36] belirtilen değerlere göre tanımlanmıştır. Çalışmada döşeme tipi olarak yüzer döşeme

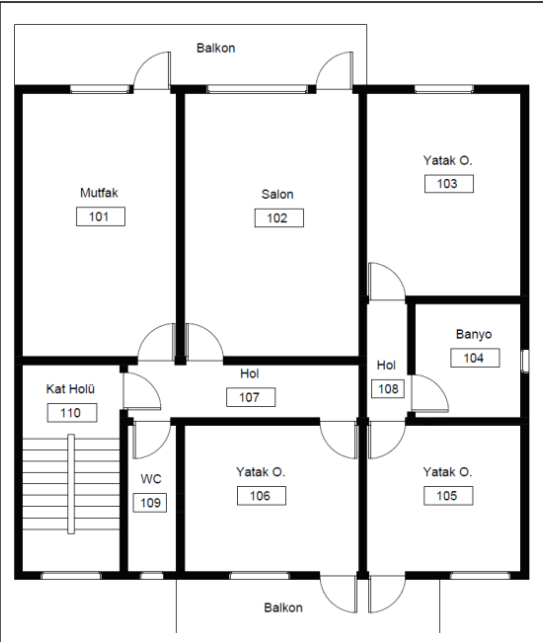

a)

\begin{tabular}{ll} 
Binanın Geometrik Özellikleri & \\
\hline Brüt uzunluk (K-G yönü) & $: 12 \mathrm{~m}$ \\
Brüt uzunluk (D-B yönü) & $: 12,5 \mathrm{~m}$ \\
Brüt yükseklik & $: 12 \mathrm{~m}(1 \mathrm{Z}+2 \mathrm{~N}$ kat) \\
Net Zemin alanı & $: 127 \mathrm{~m}^{2}$ \\
Toplam alan & $: 381 \mathrm{~m}^{2}$ \\
Çatı alanı & $: 183 \mathrm{~m}^{2}$ \\
Duvar alanı & $: 764,96 \mathrm{~m}^{2}$ \\
Cam alanı & $: 44,23 \mathrm{~m}^{2}$ \\
Pencere-Duvar Oranı & $: \% 5,78$ \\
\hline & \\
Yapı Malzemeleri Özellikleri & \\
\hline$U_{\text {Diş Duvar }}$ & $: 0,396 \mathrm{~W} / \mathrm{m}^{2} \mathrm{~K}$ \\
$\mathrm{U}_{\text {Tavan (Kullanılmayan Çatı Arası) }}$ & $: 0,25 \mathrm{~W} / \mathrm{m}^{2} \mathrm{~K}$ \\
$U_{\text {İç Duvar }}$ & $: 1,639 \mathrm{~W} / \mathrm{m}^{2} \mathrm{~K}$ \\
$U_{\text {Döșeme (Kullanılan Ị̧̇ Ortama Bitișik) }}$ & $: 2,459 \mathrm{~W} / \mathrm{m}^{2} \mathrm{~K}$ \\
$\mathrm{U}_{\text {Pencere }}$ & $: 1,96 \mathrm{~W} / \mathrm{m}^{2} \mathrm{~K}$ \\
\hline
\end{tabular}

b)

Şekil 3. Binaya Ait Bilgiler a) Kat Planı, b) Konstrüksiyon Özellikleri 
kullanılmıştır. Yüzer döşeme, binaların döşemelerinde zemin betonu atılmadan önce yalıtım malzemesinin serbest olarak döşenmesidir. Çalışmada ara katlarda yüzer döşeme uygulanması ve döşeme ile tavanda FDM kullanılmasının ortamların 1sı yüküne, ortam sıcaklığına ve enerji kullanımına etkisi incelenmiştir. Duvar, döşeme, tavan ve pencere için modelde kullanılan toplam ısı geçirme katsayıları (U), binaya ait diğer özellikler ve mimari kat planı Şekil 3'te verilmiştir. Modelde dış ortamdan iç ortam içine kapı ve pencere aralıklarından kaynaklanan hava sızıntısı değeri 0,8 (defa/saat) olarak [37], ortamlara ait 1sıtma ayar sıcaklığ 1 mutfak, salon ve yatak odaları için 20 ${ }^{\circ} \mathrm{C}$, hol için $15{ }^{\circ} \mathrm{C}$ ve banyo için $24^{\circ} \mathrm{C}$ alınmıştır [38].

\subsection{Senaryolar}

Çalışmada göz önüne alınan ilk senaryo zemin, bir ve ikinci katların aynı ayar sıcaklığında eş zamanlı olarak 1sıtıldığ 1 (ara katlarda döşeme ve tavandan 1sı geçişinin olmadığı) varsayılmıştır. İkinci senaryoda sadece birinci katın belirtilen ayar sıcak-

Tablo 1. Senaryo Detayları ve Kodları

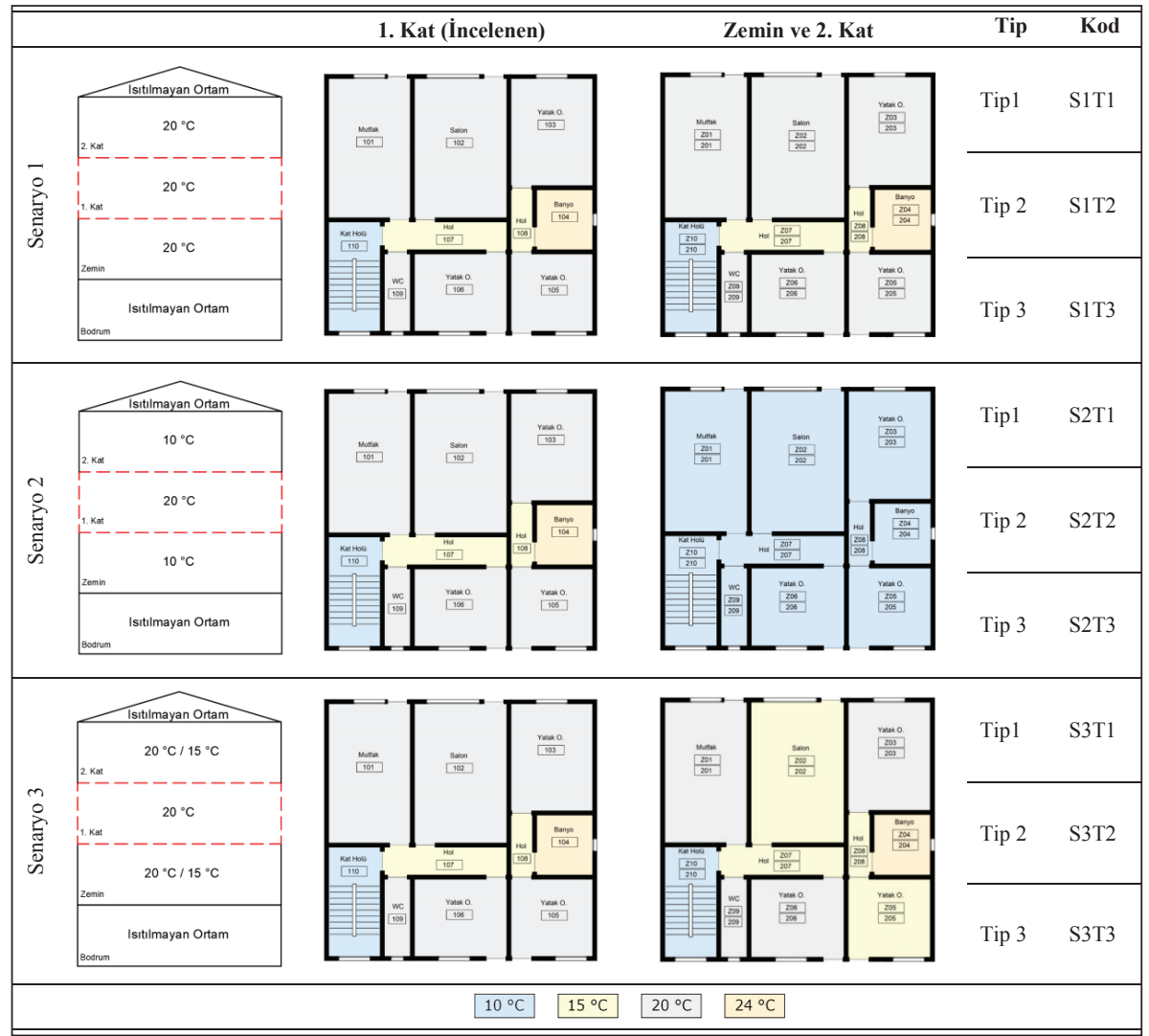




\begin{tabular}{|c|c|c|}
\hline Tip 1 & $\begin{array}{l}\text { Tip } 2 \\
\text { İç Ortam }\end{array}$ & $\underset{\text { Iç Ortam }}{\text { Tip } 3}$ \\
\hline İ̧ Ortam & Laminat Parke $(10 \mathrm{~mm}-0,23 \mathrm{~W} / \mathrm{m} . \mathrm{K})$ & Laminat Parke $(10 \mathrm{~mm}-0,23 \mathrm{~W} / \mathrm{m} . \mathrm{K})$ \\
\hline Laminat Parke $(10 \mathrm{~mm}-0,23 \mathrm{~W} / \mathrm{m} . \mathrm{K})$ & Șap (50 $\mathrm{mm}-1,4 \mathrm{~W} / \mathrm{m} . \mathrm{K})$ & $\frac{\text { Şap }(50 \mathrm{~mm}-1,4 \mathrm{~W} / \mathrm{m} . \mathrm{K})}{\text { Yüzer Döseme Levhas. } 35 \mathrm{~mm}-0.035 \mathrm{~W} / \mathrm{m} \text {. })}$ \\
\hline Șap (50 mm - $1,4 \mathrm{~W} / \mathrm{m} . \mathrm{K})$ & Yüzer Döşeme Levhası ( $35 \mathrm{~mm}$ - 0,035 W/m.K) & $\begin{array}{l}\text { Yuzer Doşeme LevhasI (35 mm -0,035 W/m.K) } \\
\text { Sap (20 mm - 1,4 W/m.K) }\end{array}$ \\
\hline Betonarme (100 mm - 2,5 W/m.K) & Şap (20 mm-1,4 W/m.K) & Betonarme (100 mm - 2,5 W/m.K) \\
\hline Siva $(20 \mathrm{~mm}-0,51 \mathrm{~W} / \mathrm{m} . \mathrm{K})$ & Betonarme (100 mm - $2.5 \mathrm{~W} / \mathrm{m} \cdot \mathrm{K}$ ) & FDM Içeren Örtü (20 mm - 0,2 W/m.K) \\
\hline \multirow[t]{2}{*}{ Iç Ortam } & Siva $(20 \mathrm{~mm}-0,51 \mathrm{~W} / \mathrm{m} . \mathrm{K})$ & Siva $(20 \mathrm{~mm}-0,51$ W/m.K) \\
\hline & İ̧ Ortam & Iç Ortam \\
\hline
\end{tabular}

lıklarında 1sıtıldığı, diğer katların ise kullanılmadığı ve $10^{\circ} \mathrm{C}$ sicaklıkta olduğu varsayılmıştır. Üçüncü senaryoda ise birinci kat belirtilen ayar sıcaklıklarında 1sıtılırken, diğer katlarda salon ve yatak odalarından birinin kullanılmadığ 1 ve $15^{\circ} \mathrm{C}$ sıcaklıkta olduğu varsayılmıştır (Tablo 1). Bu senaryolarda üç farklı döşeme tipi uygulanmıştır. Birinci döşeme tipi yalıtımın olmadığı standart ara kat döşemesidir. İkinci tip yüzer döşeme ve üçüncü tip olarak da yüzer döşemeye ek olarak içerisinde FDM içeren bir katmanın olduğu döşemedir. Döşeme tiplerine ait detaylar Şekil 4'te verilmiştir. Bina üç farklı senaryo ve bu senaryoların içinde üçer adet döşeme tipi olmak üzere toplam dokuz kodda simüle edilmiştir.

Tip 2'de kullanılan yüzer döşeme levhası olarak 35 mm kalınlığında ve 1sı iletim katsayısı $0,035 \mathrm{~W} / \mathrm{m}$.K olan taşyünü kullanılmıştır. Tip 3 'te ise bu yalıtım malzemesine ek olarak, 2 cm kalınlığında biyo-bazlı FDM uygulanmıştır. FDM performans gösterebilmesi için erime sıcaklığı iç ortam sıcaklığına yakın olmalıdır [39]. Bu nedenle $21^{\circ} \mathrm{C}$ erime sıcaklığına sahip FDM kullanılmıştır. Çalışmada FDM, betonarmenin altında bir örtü katmanı içerisinde uygulanmıştır (Şekil 5). Döşeme tiplerinin ısı ge-

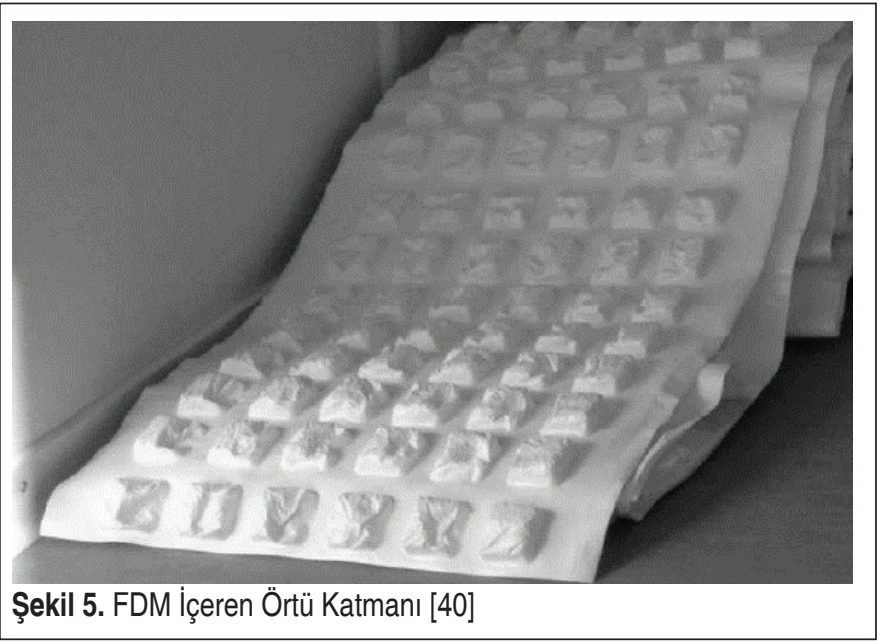


çirme katsayıları $\mathrm{U}_{\text {Döșeme Tip } 1}=2,459 \mathrm{~W} / \mathrm{m}^{2} \mathrm{~K}, U_{\text {Dösseme Tip } 2}=0,704 \mathrm{~W} / \mathrm{m}^{2} \mathrm{~K}$ ve $U_{\text {Dösseme Tip } 3}$ $=0,656 \mathrm{~W} / \mathrm{m}^{2} \mathrm{~K}^{\prime}$ dir .

\section{BULGULAR}

\subsection{Isı Yükleri}

Dokuz farklı kodda simüle edilen binada, öncelikle birinci kattaki ortamların 1sı yükleri belirlenmiştir. Isı yükleri yıl içinde dış ortam sıcaklığının en düşük olduğu zaman için hesaplanmıştır. İç ortam sıcaklıkları ise ayar sıcaklığı baz alınarak hesaplanmaktadır. Isıl denge yaklaşımındaki denklemler çözdürülerek elde edilen ortamlara ait 1sı yükleri Şekil 6'da verilmiştir.

Göz önüne alınan ilk senaryoda zemin, bir ve ikinci katlar aynı ayar sıcaklığında eş zamanlı olarak 1sıtılmaktadır. TS2164'te belirtilen statik hesap yöntemi ile 1sı kayıpları hesaplandığında, ara katlarda döşeme ve tavandan 1sı geçişinin olmaması beklenir. Ancak çalışmada dinamik hesap yöntemi kullanıldığı için birinci kata komşu katların ortam sıcaklıkları ayar sıcaklığından farklılık gösterebilmektedir. Zemin katın altındaki (bodrum) ve ikinci katın üstündeki (çatı arası) 1sıtılmayan ortamlar, bu katların ortam sıcaklıklarını ve 1sı yüklerini etkilemektedir. Bu nedenle bu katlardaki ortamların 1Sı yükleri de birinci kattaki ortamlardan farklı olmakta ve ara katlarda döşeme ve tavana yalıtım uygulamanın önemi ortaya çıkmaktadır. İlk senaryoda S1T1 kodlu modelde döşemede ve tavanda yalıtım bulunmamaktadır. Döşeme ve tavana yalıtım

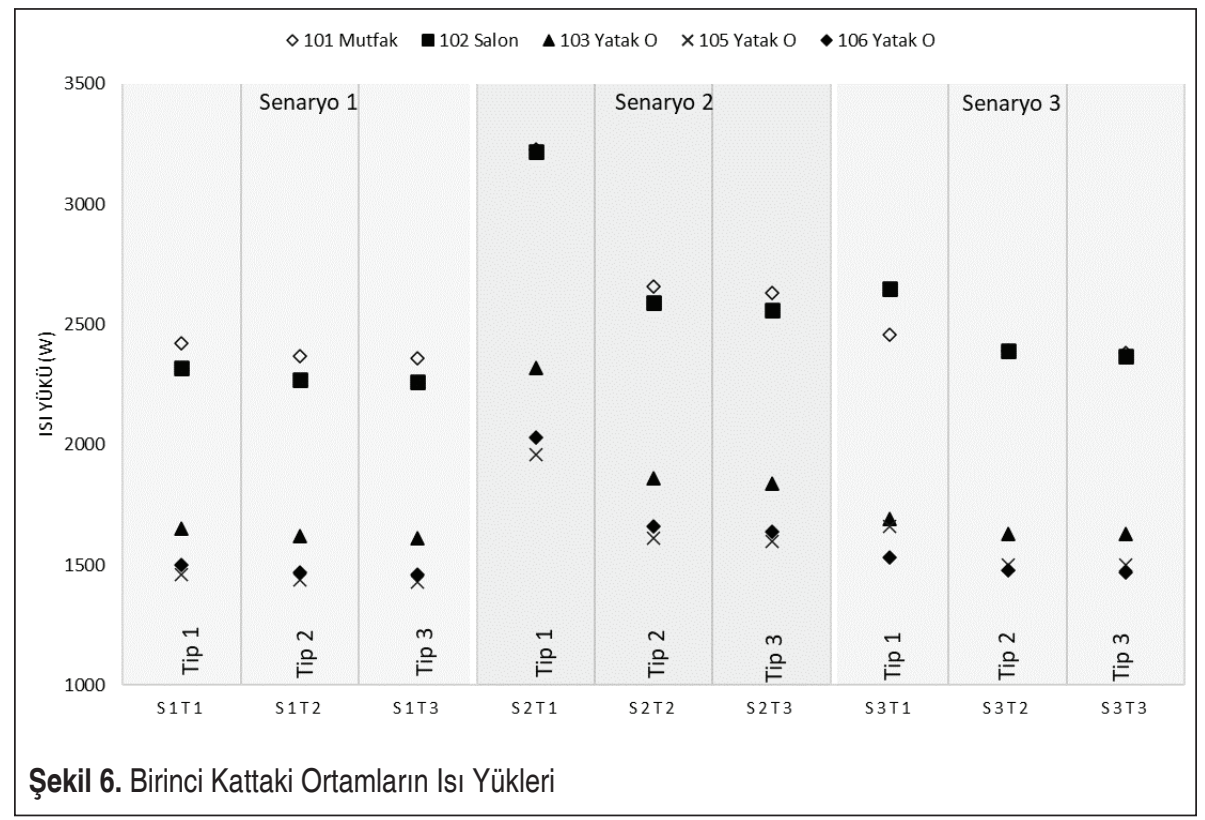


eklenmesiyle oluşturulan S1T2 kodlu model tüm ortamların 1sı yükünü ortalama \%2 azaltmaktadır. S1T3'te ise döşeme içerisinde FDM içeren bir katman bulunmaktadır. $\mathrm{Bu}$ durumda S1T1'e kıyasla tüm ortamlar için 1sı yükü ortalama \%2,5'lik azalmıştır. Döşemeye FDM'nin eklenmesi toplam 1sı geçirme katsayısını düşürdügü için ortamların 1sı yükü düşmektedir. Buna ek olarak ortam sıcaklığının artmasıyla, FDM katı halden sıvı hale geçerken bir miktar enerjiyi absorbe etmektedir. Ortam sıcaklığı azalmaya başladığında ise FDM sıvı halden katı hale geçmekte ve daha önce absorbe ettiği enerji ortama geçmektedir. Bu sayede ortamın maksimum 1sı yükünün düşmesini sağlamaktadır. İkinci senaryoda, bina tasarlanırken tüm katların eş zamanlı 1sıtılacağ1 varsayılmasına rağmen sadece birinci kat ısıtılmaktadır. Bu durumda döşemede yalıtımın olmadığı S2T1'de ortamların ortalama 1S1 yükü, S1T1'e göre \%37 oranında artmıştır. Döşeme ve tavana yalıtımın eklenmesiyle bu oran \%11'e, FDM eklenmesiyle ise \%9,8'e düşmüştür. Üçüncü senaryoda ise kat 1sıtması yapılan binalarda sıklıkla karşılaşılan ve kullanıcı davranışlarına göre değişen bazı ortamların 1sıtılması, bazı ortamların 1sitılmaması durumudur. Senaryoya göre zemin ve ikinci katta bulunan salon ve yatak odalarından bir tanesi isitılmamaktadır. Bu durumda birinci katta bulunan salon ve yatak odasının ortam sıcaklığı düşmekte ve 1sı yükü artmaktadır. Dolaylı olarak ise bu ortamlara komşu ortamların da 1sı yükü etkilenmektedir. Böyle bir senaryoda döşeme ve tavana yalıtımın uygulanmadığ1 S3T1'de 1s1 yükü S1T1'e göre tüm ortamlar için ortalama \%6,8 artmaktadır. Döşeme ve tavana yalıtımın eklenmesiyle bu oran \%0,4'e düşmüştür. FDM eklenmesi ile de S1T1 ile aynı seviyeye gelmiştir.

\subsection{Ortam Sicaklıkları}

İç ortam ve dış ortam sıcaklığı, ayar sıcaklığı, 1Sı kaybı, ortamdaki hava sızıntıları, 1S1 yayan ekipmanlar vb. parametrelere ve zamana bağlı olarak hesaplanmaktadır. Çalışmada yüzer döşemenin ve döşemede FDM kullanılmasının 1sı yüküne, ortam sıcaklığına ve ısıtma için enerji kullanımına etkisi incelendiği için, ortam sıcaklıkları dış ortam sıcaklığının en düşük olduğu gün boyunca elde edilmiştir. Üçüncü senaryoda, zemin ve ikinci katta bulunan salon ve yatak odalarından birinin 1sitılmamasından dolayı bu iki ortamın saatlik sıcaklık değişimi dokuz farklı koda göre Tablo 2'de verilmiştir.

Zemin katın altında bulunan bodrum ve ikinci katın üstünde bulunan çatı arasının 1sıtılmayan ortamlar olmasından dolayı dış ortam sıcaklığgndaki değişim bu ortamların sıcaklıklarını etkilemektedir. Bu değişim ise dolaylı olarak bütün katlardaki ortam sıcaklıklarının ayar sıcaklığından farklı olmasının sebeplerinden biri olmuştur. Her üç senaryoda da döşeme tipi fark etmeksizin ortam sıcaklıkları zamana (dış ortam sıcaklığına) bağlı olarak değişmiştir. Ancak döşeme ve tavanda yalıtımın olmadığı S1T1, S2T1 ve S3T1 kodlu modellerde sıcaklık fark1 çok daha fazla olmuştur. Ayar sicaklığg $20^{\circ} \mathrm{C}$ olan salona ait ortam sicaklığ $\mathrm{S} 1 \mathrm{~T} 1$ 'de gün boyu ortalama $18,8^{\circ} \mathrm{C}$ 'de kalırken S2T1'de $17,6{ }^{\circ} \mathrm{C}$, S3T1'de ise $18,4{ }^{\circ} \mathrm{C}$ olmuştur. Aynı ayar sıcaklığındaki 
Tablo 2. Ortamların Saatlik Sıcaklık Değişimi

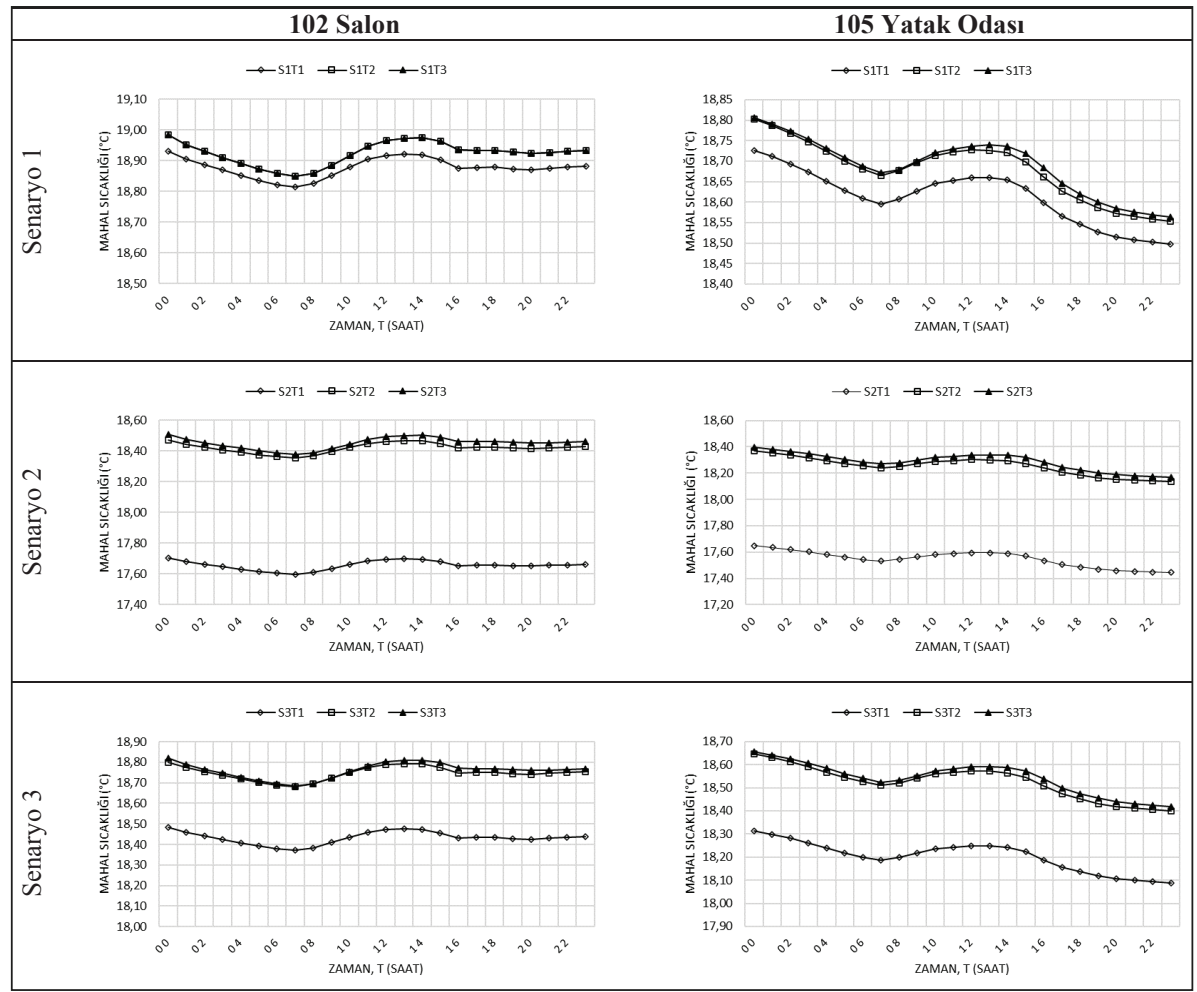

yatak odasına ait ortam sıcaklığg ise $\mathrm{S} 1 \mathrm{~T} 1$ 'de gün boyu ortalama $18,6{ }^{\circ} \mathrm{C}$ 'de kalırken $\mathrm{S} 2 \mathrm{~T} 1$ 'de $17,5^{\circ} \mathrm{C}, \mathrm{S} 3 \mathrm{~T} 1$ 'de ise $18,2^{\circ} \mathrm{C}$ olmuştur. Döşeme ve tavana yalıtımın eklenmesiyle ortam sıcaklıkları ayar sıcaklıklarına yaklaşmıştır. Ayar sıcaklıklarına en yakın değerler ise FDM'nin kullanılmasıyla elde edilmiştir. FDM katmanı döşemenin toplam 1sı geçirme katsayısını düşürmesinin yanında, erime sırasında enerjiyi absorbe etmesinden ve katılaşma sırasında absorbe ettiği enerjinin ortama geçmesinden dolayı sıcaklık dalgalanmalarını da azaltmaktadır. Bu sayede ortamlar ayar sıcaklıklarına daha yakın sıcaklıklarda kalabilmiştir.

\subsection{Yıllık Isıtma Enerjisi Kullanımı}

Binanın enerji kullanımı, ortamların 1sı yüklerinin saatlik olarak yıl boyu hesaplanması ve ısıtma sisteminin tipine bağlı olarak hesaplanmıştır. Çalışmada yüzer döşemenin ve döşemede FDM kullanılmasının enerji kullanımına etkisi 4. derece gün bölgesinde incelendiği için enerji kullanım hesabı sadece 1sıtma için yapılmıştır. Binada her bir daire (kat) bağımsız olarak ısıtılmaktadır. Dolayısıyla her bir dairedeki kullanıcılarının ısıtmaya olan yaklaşımı diğer dairelerin de enerji kullanımını etkilemektedir. 


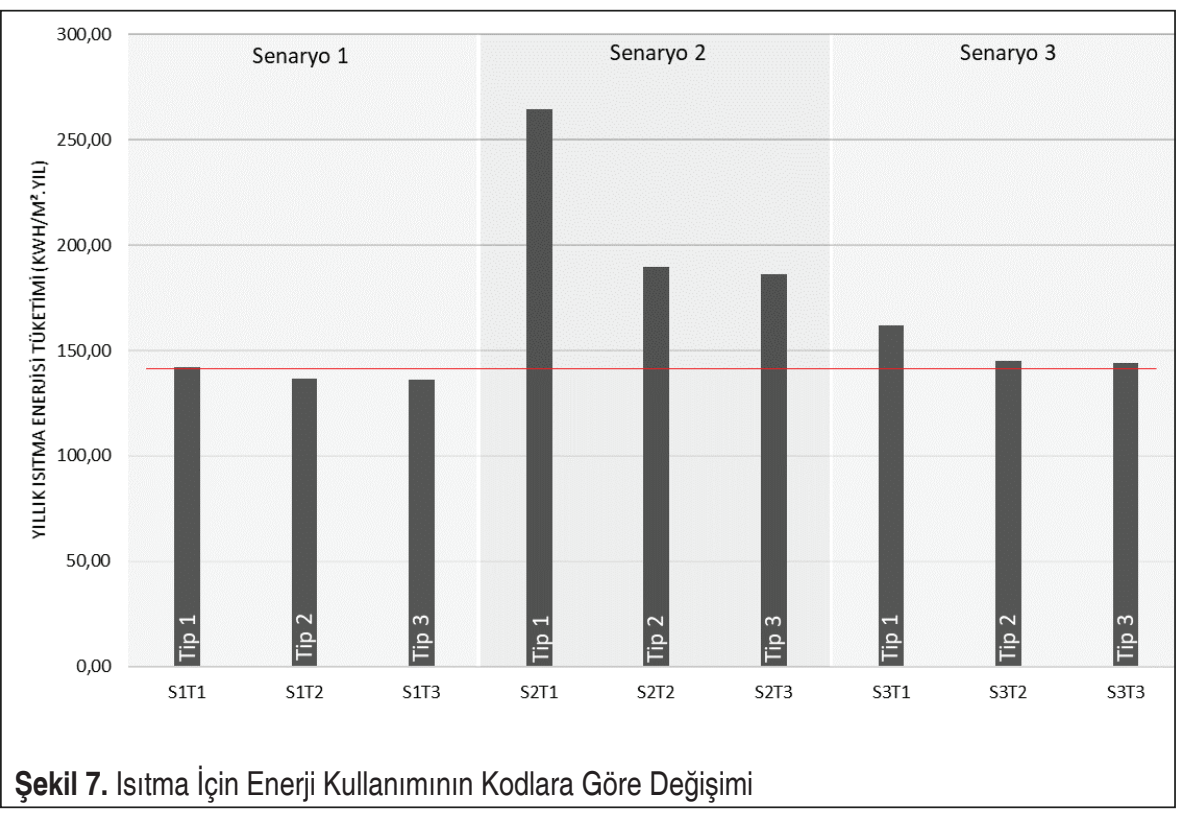

Yüzer döşemenin ve FDM'nin enerji kullanımına etkisini belirlemek için, bina dokuz farklı kodda simüle edilmiş ve birinci kata ait sonuçlar metrekare başına Şekil 7'de verilmiştir.

Birinci senaryoda döşemede ve tavanda yalıtımın olmadığı S1T1 kodlu modele göre, döşemeye ve tavana yalıtım eklenmesiyle oluşturulan S1T2 kodlu modelde 1sıtma için enerji kullanımı \%3,6, FDM katmanının olduğu S1T3’te ise \%4 azalmaktadır. Bu azalış bütün katların eş zamanlı olarak ısıtıldığı binalarda bile döşeme ve tavana yalıtım uygulanmasının önemini göstermektedir. İkinci senaryoda, bina tasarlanırken tüm katların eş zamanlı ısıtılacağı varsayılmasına rağmen sadece birinci kat 1sıtılmaktadır. $\mathrm{Bu}$ durumda döşemede yalıtımın olmadığı S2T1'de birinci katın 1sıtma için enerji kullanımı, S1T1'e göre \%86 oranında artmıştır. Döşeme ve tavana yalıtımın eklenmesiyle bu artış \%33'e, FDM eklenmesiyle ise \%31'e düşmüştür. Üçüncü senaryoda ise S3T1'de 1sıtma enerjisi kullanımı S1T1'e göre \%14,2 artmıştır. Döşeme ve tavana yalıtımın eklenmesiyle bu oran \%2,1'e düşerken, FDM eklenmesi ile \%1,4'e düşmüştür. Binada hangi 1sıtma sistemi kullanılırsa kullanılsın döşeme ve tavana uygulanan yalıtım ve FDM uygulaması enerji kullanımını düşürmektedir.

\section{SONUÇ}

Her katta bireysel ısıtma sisteminin bulunduğu binalarda, 1sıtma sisteminin kontrolü kullanıcılarda olmaktadır. Kullanıcılar günlük yaşamlarına göre ısıtma sistemini açıp kapatmakta veya bazı ortamları 1sıtırken bazı ortamları 1sıtmamaktadır. Bu tip işletme 
koşulları ise alt ve üst katta bulunan dairelerin 1 sıl konforunu etkilemektedir. Her katın eş zamanlı 1sıtıldığ düşünülerek yapılan hesaplar sonucu belirlenen 1sıtma sisteminin ve ortamlardaki 1sıtıcıların (radyatör, fancoil, klima vb.) kapasiteleri, böyle durumlarda ortamları istenilen sıcaklıklara getirmekte yetersiz kalabilmektedir. Çalışma kapsamında böyle bir durumun da olduğu farklı senaryolar üzerinde çalışılmıştır. Her katın eş zamanlı 1sıtıldığı, alt ve üst katların hiç 1sıtılmadığı ve alt ve üst katlarda bazı ortamların 1sıtılmadığı üç farklı senaryo oluşturulmuştur. Bu senaryolar yalıtımsız, yalıtımlı ve yalıtıma ek FDM içeren bir katmanın olduğu üç farklı döşeme tipinde toplam dokuz farklı kodda modellenerek simüle edilmiştir. Çalışmanın sonunda döşeme ve tavanda yalıtım ve FDM bulunmasının ortamların 1sı yüklerini düşürdüğü belirlenmiştir. Aynı zamanda ortam sıcaklıklarının ayar sıcaklığına daha yakın olmasını sağlayarak ısıl konfor koşullarının elde edilmesine katkı sağlanmıştır. Son olarak yıllık enerji kullanımına etkisinin belirlenmesiyle döşeme ve tavanlarda yalıtım ve FDM kullanımının önemli olduğu anlaşılmıştır. Enerji kullanımının azaltılması sayesinde fosil kaynaklarının kullanımı ve sera gazı üretimi azalacaktır. Bunlara bağlı olarak ise iklim değişikliği üzerindeki etkiler azalacaktır.

\section{SEMBOLLER}

COP : Sistemdeki cihazın etkinlik katsayısı

IDK : Isıtma sistemi dağıtım kaybı

$F_{j} \quad: \quad$ Akı CTF katsayıs $1, \mathrm{j}=0,1, \ldots$ nq.

$T_{i} \quad$ : İç yüzey sıcaklığ

$T_{o} \quad: \quad$ Diş yüzey sıcaklı̆̆1

$T_{z} \quad: \quad$ İç ortam sicaklığı

$T_{s i} \quad: \quad$ Duvarın iç ortamdaki yüzey sıcaklığı

$T_{z i} \quad: \quad$ Komşu iç ortam sıcaklığı

$T_{\infty} \quad: \quad$ Diş ortam sıcaklığı

$T_{\text {sup }} \quad: \quad$ Isıtma cihazı tarafından sağlanması gereken havanın sıcaklığ

$q{ }^{\prime}{ }_{L W X} \quad$ : Ortam yüzeyleri arasında net uzun dalga radyasyonla 1sı girişi

$q{ }^{\prime}{ }_{S W} \quad: \quad$ Ortam içindeki aydınlatmalardan yüzeylere net kısa dalga radyasyonla 1Sı girişi

$q{ }^{\prime \prime W S} \quad$ : Ortam içindeki ekipmanlardan uzun dalga radyasyonla 1sı girişi

$q{ }^{\prime}{ }_{\text {sol }} \quad$ : Yüzeyde absorbe edilen güneş radyasyonuyla ısı girişi

$q{ }^{\prime}{ }_{\text {conv }} \quad$ : İç ortamdan taşınımla 1sı girişi 
$q{ }_{k i} \quad$ : Duvarda iletimle 1 sı geçişi

$q{ }_{\text {asol }} \quad$ : Absorbe edilmiş direkt ve dağınık güneş (kısa dalga boyu) radyasyonuyla 1sı girişi

$q{ }_{L W R} \quad: \quad$ Diş havaya net uzun dalga (1sil) radyasyonla 1sı geçişi

$q{ }^{\prime}{ }_{\text {conv }} \quad$ : Diş havaya taşınımla 1sı geçişi

$q "{ }_{k o} \quad$ : Duvarda iletimle 1sı geçişi

$\dot{Q}_{s y s} \quad: \quad$ Isitma sisteminden ortama verilmesi gereken 1S1

$\dot{Q}_{\text {kullanım }}$ : Isıtma için yıllık enerji kullanımı

$\dot{Q}_{\text {saatlik,yük }}:$ Saatlik 1sı yükü

$X_{j} \quad$ : $\quad$ Dış CTF katsayısı, $\mathrm{j}=0,1, \ldots$ nz.

$Y_{j} \quad: \quad$ Çapraz CTF katsayısı, $\mathrm{j}=0,1, \ldots$ nz.

$Z_{j} \quad$ : $\quad$ İç CTF katsayısı, j=0,1,..nz.

\section{KAYNAKÇA}

1. Kyoto Protokolü, 1998. "Kyoto Protocol to the United Nations Framework Convention on Climate Change", http://unfccc.int/resource/docs/convkp/kpeng.pdf, erişim tarihi 05.03.2020.

2. Paris İklim Değişikliği Anlaşmas1, 2015. "Paris Agreement," https://unfccc.int/sites/def ault/files/english_paris_agreement.pdf, erişim tarihi 08.02.2020.

3. EPBD, 2002. "Directive 2002/91/EC of the European Parliament and of the Council of 16 December 2002 on the energy performance of buildings," Official Journal of the European Union.

4. EPBD recast, 2010. "Directive 2010/31/EU of the European Parliament and of Council of 19 May 2010 on the energy performance of buildings (recast)," Official Journal of the European Union.

5. Kaynaklı, O. 2008. "A Study on Residential Heating Energy Requirement and Optimum Insulation Thickness,” Renewable Energy, vol. 33, p. 1164-1172.

6. European Union, 2020. "Topics of the European Union," https://europa.eu/european-union/topics_en, erişim tarihi: 06.01.2020.

7. Cheung, C.K., Fuller, R.J. Luther, M.B. 2005. "Energy-Efficient Envelope Design for High-Rise Apartments," Energy and Buildings, vol. 37, p.37-48.

8. Daouas, N. 2011. "A Study on Optimum Insulation Thickness in Walls and Energy Savings in Tunisian Buildings Based on Analytical Calculation of Cooling and Heating Transmission Loads," Applied Energy, vol. 88, p. 156-164.

9. Yaşar, Y., Maçka Kalfa, S. 2012. "The Effects of Window Alternatives on Energy Effi- 
ciency and Building Economy in High-Rise Residential Buildings in Moderate to Humid climates," Energy Conversion and Management, vol. 64, p. 170-181.

10. Delmastro, C., Mutani, G., Schranz, L. 2015. "Advantages of Coupling a Woody Biomass Cogeneration Plant With a District Heating Network for a Sustainable Built Environment: A Case Study in Luserna San Giovanni (Torino, Italy)," Energy Procedia, vol. 78, p. $794-799$.

11. Ferrara, M., Fabrizio, E. 2017. "Building Simulation (Innovation, Rapid Design, Design Support) \& ICT Cost Optimal nZEBs in Future Climate Scenarios," Energy Procedia, vol. 122 p. 877-882.

12. Kurnitski, J., Kuusk, K. 2014. "Energy and Investment Intensity of Integrated Renovation and 2030 Cost Optimal Savings," Energy and Buildings, vol. 75, p. 51-59.

13. Çuhadaroğlu B. 1997. "Kat Isıtmasında Tasarım Kriterleri," Makine Mühendisleri Odas1 97' Teskon Ek Bildiriler Kitab1, s. 905-913.

14. IEA, 2017. "International Energy Agency Energy Technology Perspectives," https:// www.iea.org/topics/energy-technology-perspectives, sonerişim tarihi: 20.03.2020.

15. The Strategic Energy Technology (SET) Plan, 2017. "Energy Research and Innovation in Europe," European Commission.

16. Kosny, J. 2015. "PCM-Enhanced Building Components An Application of Phase Change Materials in Building Envelopes and Internal Structures," ISBN 978-3-319-14286-9, Springer International Publishing, Switzerland.

17. Depe, D. 2017. "Yenilikçi isı depolama sistemi faz değiştiren malzemelerin bina enerji verimliliği üzerindeki etkisinin analizine yönelik yaklaşım: Diyarbakır ve Erzurum örnekleri, “Yüksek Lisans, İstanbul Teknik Üniversitesi, İstanbul.

18. Alam, M., Jamil, H., Sanjayan, J., Wilson, J. 2014. "Energy saving potential of phase change materials in majör Australian Cities," Energy and Buildings, vol. 78, p.192-201.

19. Evola, G., Marletta, L., Sicurella, E. 2014. "Simulation of a Ventilated Cavity to Enhance the Effectiveness of PCM Wallboards for Summer Thermal Comfort in Buildings," Energy and Buildings, vol. 70, p. 480-489.

20. Auzeby, M., Wei, S., Underwood, C., Chen, c., Ling, H., Pan, S., Ng, B., Tindall, J., Buswell, R, 2017. "Using phase change materials to reduce overheating issues in UK residential buildings," Energy Procedia, vol. 105, p. 4072 - 4077.

21. Li, L., Yu, H., Liu, R. 2017. "Research on Composite-Phase Change Materials (PCMs)Bricks in the West Wall of Room-Scale Cubicle: Mid-Season and Summer Day Cases," Building and Environment, vol. 123, p. 494-503.

22. Wang, Q., Wu, R., Wu, Y., Zhao, C.Y. 2018. "Parametric Analysis of Using PCM Walls for Heating Loads Reduction," Energy \& Buildings, vol. 172, p. 328-336. 
23. Bianco, L., Komerska, A., Cascone, Y., Serra, V., Zinzi, M., Carnielo, E., Ksionek, D. 2018. "Thermal and Optical Characterisation of Dynamic Shading Systems With PCMs Through Laboratory Experimental Measurements," Energy and Buildings, vol. 163, p. 92-110.

24. Zhu, L., Yang, Y., Chen, S., Sun, Y. 2018. "Numerical Study on the Thermal Performance of Lightweight Temporary Building Integrated with Phase Change Materials," Applied Thermal Engineering, vol. 138, p. 35-47.

25. Thantong, P., Khedari, J., Chantawong, P. 2018. "Study of Solar- PCM Walls for Domestic hot Water Production Under the Tropical Climate of Thailand," Materials Today: Proceeding, vol. 5, p. 14880-14885.

26. Iten, M., Liu, S., Shukla, A. 2016. "Experimental Study on the Thermal Performance of Air-PCM Unit," Building and Environment, vol. 105, p. 128-139.

27. Devaux, P., Farid, M.M. 2017. "Benefits of PCM Underfloor Heating with PCM Wallboards for Space Heating in Winter," Applied Energy, vol. 191, p. 593-602.

28. Maccarini, A., Hultmark, G., Bersgoe, N. C., Afshari, A. 2018. "Free Cooling Potential of a PCM-Based Heat Exchanger Coupled with a Novel HVAC System for Simultaneous Heating and Cooling of Buildings," Sustainable Cities and Society, vol. 42, p. 384-395.

29. Jaworski, M. 2019. "Mathematical Model of Heat Transfer in PCM Incorporated Fabrics Subjected to Different Thermal Loads," Applied Thermal Engineering, vol. 150, p. 506511.

30. Biswas, K., Abhari, R. 2014. "Low-Cost Phase Change Material as an Energy Storage Medium in Building Envelopes: Experimental and Numerical Analyses," Energy Conversion and Management, vol. 88, p.1020-1031.

31. Kong, X., Lu, S., Li, Y., Huang, J., Liu, S. 2014. "Numerical study on the thermal performance of building wall and roof incorporating phase change material panel for passive cooling application,” Energy and Buildings, vol. 81, p. 404-415.

32. Solgi, E., Memarian, S., Moud, G. N. 2018. "Financial Viability of PCMs in Countries with Low Energy Cost: A Case Study of Different Climates in Iran,” Energy \& Buildings, vol. 173, p. 128-137.

33. Karaoulis, A. 2017. "Investigation of Energy Performance in Conventional and Lightweight Building Components with the use of Phase Change Materials (PCMS): Energy Savings in Summer Season", Procedia Environmental Sciences, 38, 796-803.

34. Strand, R.K., Pedersen, C.O., Crawley, D.B. 2001. "Modularization and simulation techniques for heat balance based energy and load calculation programs: the experience of the ashrae loads toolkit and energyplus," Seventh International IBPSA Conference, August 13-15, 2001, Brazil.

35. EnergyPlus Documentation, 2020. "EnergyPlus Documentation Engineering Reference," 
https://energyplus.net/sites/all/modules/custom/nrel_custom/pdfs/pdfs_v9.3.0/EngineeringReference.pdf, son erişim tarihi: 15.04.2020.

36. TS 825 Binalarda Isı Yalıtım Kuralları, 2009. Türk Standartları Enstitüsü, Ankara.

37. Binalarda Enerji Performansı Yönetmeliği (BEP TR), 2008. Bayındırlık ve İskan Bakanlığı, Türkiye Cumhuriyeti Resmi Gazetesi, Ankara.

38. TS 2164 Kalorifer Tesisatı Projelendirme Kuralları, 1983. Türk Standartları Enstitüsü, Ankara.

39. Kuznik, F., Virgone, J. 2009. "Experimental investigation of wallboard containing phase change material: Data for validation of numerical modeling," Energy and Buildings, vol. 41, p. 561-570.

40. DesignBuilder User Guide, 2020. "DesignBuilder User Guide," https://designbuilder. co.uk/helpv6.0/, erişim tarihi: 01.04.2020. 